\title{
Urban Railway Connection: Opportunities, Challenges, Development Opportunities
}

\author{
Nguyen Duc Tam* \\ University of Transport and Communications, Vietnam \\ *Corresponding Author \\ Nguyen Duc Tam

\section{Article History} \\ Received: 06.07.2020 \\ Accepted: 13.07 .2020 \\ Published: 16.07.2020

\begin{abstract}
Urban railways play a huge role in urban transport. Over the past years, traffic congestion in two major cities of Vietnam, Hanoi and Ho Chi Minh City has often occurred, adversely affecting the development of the two cities in particular and of the whole country in general. This study focuses on analyzing the urban railway connection when completed and put into use, the difficulties that will be encountered at the same time as new opportunities are opened and its impact on urban space of the two largest cities in Vietnam are Hanoi and Ho Chi Minh City. However, due to the condition of this time, the study focused only on the urban railway of Hanoi - the capital of Vietnam.
\end{abstract}

Keywords: Urban railway, opportunities, challenges, urban space, Hanoi, Vietnam.

\section{INTRODUCTION}

To meet the needs of sustainable development, increase the capacity of the public transport system, the effective method is the urban railway is connected synchronously with other systems.

Since the expansion of the administrative boundaries, the population of Hanoi has increased to more than 7.6 million people in 2017, expected to reach 9 million in 2030. With strong growth in the urban population. As such, only until 2020, it is expected that about 25,000-50,000 passengers/hour need to be moved within the inner city.

In order to meet this demand, Hanoi Transport Planning to 2030, vision to 2050 were approved by the Prime Minister in 2016. In particular, the level of traffic distribution is one of the important goals. According to 2030, urban railways will account for $30 \%$ of the total travel volume of people for the nuclear city, followed by buses with $25 \%$. For satellite cities, the figures are $15 \%$ and $25 \%$ respectively.

Hanoi urban railway system was born in the context of not having much preparation for the land fund as well as a sense of development control in order to create an effective connection between the station system and the centers of people concentration urban. As a temporary solution, urban railway lines and railway stations are planned between the main roads or underground because there is no land and planning in advance. There have been many calls for urban railway development combined with urban restructuring, but there is no pressure on urban railway projects to ensure the effective connection with the city.

\section{LiTERATURE REVIEW}

The Hanoi General Plan 2030 lists a series of general requirements for urban railway construction and development - but has not paid much attention to the feasibility of the requirements or proposed coordination measures for implementation. The urban railway is assumed to be an infrastructure that can be implemented and implemented independently through specialized transport projects of HAIDEP, TEDI, and other units, while the coverage and quality of these projects really matter. Rather, in order to effectively promote the urban railway system, it is necessary to combine the station system planning with the renovation and urban planning - which includes land fund preparation,

Copyright @ 2020: This is an open-access article distributed under the terms of the Creative Commons Attribution license which permits unrestricted use, distribution, and reproduction in any medium for non commercial use (NonCommercial, or CC-BY-NC) provided the original author and source are credited. 
space system development planning. public and walking routes, crowded areas such as markets, supermarket centers, service centers, offices, hospitals, schools, etc. Doing so will enhance the attractiveness, comfort, and reasonable of walking spaces, making Hanoi really suitable for walking lifestyle and public transport, in line with the current trend of green, sustainable, and energy-saving development of the world.

However, this is not a simple task and depends much on the economic potential of the city. What should be done in the immediate future is to identify outstanding factors that are likely to have a fundamental effect on the task performance - in order to develop appropriate control solutions.

Currently, the main public transport system of the city is the bus and fast bus (BRT) with a total of 112 routes, the coverage reaches $68.5 \%$ and only meets $10 \%$ of travel needs people's back. In the future when the population as well as the planned target of public transport use increases, public transport needs to be further developed. Otherwise, Hanoi will easily fall into the situation of "no way to go".

\section{Research Content}

Transport planning of Hanoi to 2030, vision to 2050

With the Hanoi Transport Plan to 2030, with a vision to 2050, the metro system with 9 routes is expected to be the backbone of the city's transportation, linked to buses and other roads. Other modes of public transport. When completed, the metro system will form the main axes of the public passenger transport network in the capital.

A complete metro system will connect, help travel between residential areas, industrial parks, schools, hospitals, etc as well as between the nuclear city and the surrounding satellite cities become easier [1,2]. Easy, more convenient. Metro also contributes to the socio-economic development of areas and urban areas along the route.

With a transport capacity of up to 30,000 passengers/hour/direction, the metro will meet the needs of large and long-distance transport [2]. Due to the use of a private road, the metro is not affected by congestion, flooding (with a flood level below $60 \mathrm{~cm}$ ) or other traffic incidents, passengers will always be present at the destinations according to the scheduled schedule.

Moreover, the ship has a large space to create relaxation for users. The train moves smoothly with a stable speed so passengers can comfortably relax during the journey. The system is designed to be friendly to the elderly, pregnant women, and people with disabilities.

The bus system includes BRT and small buses with the advantage of flexibility, able to connect short routes to meet the needs of moving between points, not on the railway.

The bus system is classified into 3 types: Class 1 bus route with the capacity to transport about 80 passengers/vehicle; secondary bus route with the carrying capacity of 40-60 passengers/car and the tertiary bus route, enters small roads with the carrying capacity of about 30 passengers/vehicle. These three bus hierarchies will be a complete addition to the urban railway system [2].

With their own characteristics, the two metro and bus vehicles complement each other, making the pair greatly increase the capacity as well as the utility of the city's public transport system [3]. Not only meeting the travel needs of the people of the capital, but urban railways also help improve the green living environment, improve the quality of life while helping to reduce the number of individual cars.

\section{Factors affecting Hanoi urban railway}

Capital: Capital is often considered the most important factor in the construction of urban infrastructure, especially the urban railway system. In fact, the rate of return on capital is important [4]. The key issue is the guidelines and mechanisms that allow the exploitation of the benefits that can be generated from urban railway projects. This is something many experts have mentioned. Of these, the approved urban railway network plays a decisive role in the future, because once the planned roads are built, there are not many opportunities to change or adjust.

With the option of arranging major urban railways in parallel with the main roads, these urban roads basically do not open more opportunities for land fund development and urban improvement but only enhance add accessibility to developed buildings, have good access along the big road - which is not a major concern for the owners [4, 5]. Therefore, it is difficult for urban railway projects to exploit capital from the added value of the land lots that urban railways go through. 
Technology and management: In official statements, the role of technology and management of urban railways are often overemphasized, considering these as the most important factors. These should only be considered as projectspecific issues.

For urban and urban futures, it is important to be consistent with the level of operation, efficiency, and impact of the urban railway system. Thus, a system of requirements is the basis for management and development; specific mechanisms to encourage development; and specific concrete support commitments - which are really necessary to ensure the competitiveness, relevance, and future of railway development.

\section{The prominent impact of urban railway on transport}

Station and the link between urban railway and urban areas: This is a matter that many experts consider to be the most important to promote the efficiency of urban railway system but little is mentioned in practice - mostly due to the lack of Prepared in advance, the limited purpose of urban railway projects, as well as the complexity of the problem. In the long run, the efficiency and revenue of the urban railway system depend largely on the comfort and suitability of the connections between the urban railway station and the urban area, namely: walking routes, crowded and operating centers, parking lots, transit systems [4]. Although it may not be done, right now we have to consider the development of the area around the station for the next 20 years to take appropriate control measures.

Leaving private vehicles and using public transport: Most studies on this issue agree that the main reason people use motor vehicles (especially motorbikes) is due to their flexibility. , convenient, suitable for the travel purpose of the majority of people. Therefore, besides the "negative" measures to make it difficult for individual vehicles to become more inconvenient - the main problem is to build a public transport system that is flexible, convenient, and more suitable for the Daily travel destination of different objects [3]. When the quality of transport means and directions of the public transport (except urban railways) can be adjusted without much difficulty - the quality of public transport walking and parking spaces is actually a more decisive factor the tendency to abandon personal means in the long run.

Spacewalk: Supporting the development of pedestrian spaces is the policy of Hanoi government and planning with the recent result of the establishment of more walking streets in the center of Hanoi. However, for people to really walk every day, walking spaces must exist everywhere, must meet the daily travel needs of many people, connect well with public transportation, and are comfortable and convenient that people find walking really more appealing.

In addition to many design principles of walking space organizations can be easily found in specialized documents. Particular attention should be paid to the development of walking space in Hanoi in particular and Vietnam in general as the negative effects of a hot and humid climate. Without a solution to make the walk spaces dry, cool, shady, every other effort would not make much sense - because walking in the sun, in hot and humid climates, is a pain for everyone [4]. This explains why most people often walk, practice running in the early morning or late afternoon; or just like to stroll around the large lake with many trees.

Certainly, Hanoi will need a lot of time and effort to build a quality walking space system for people to switch to walking $[5,6]$. For the future, from now on, Hanoi needs to set up a plan of the pedestrian space network in combination with the organization of public transport system, tourism, social infrastructure, and trade in services - with important goals being standard the land fund, orientation for renovation and new construction. Regulations need to be built on the construction of pavement roofs or independent walkways to provide a consistent basis for urban management.

\section{DISCUSSION}

\section{Development Context}

Hanoi is now a combination of planned areas (old town, old street, and new urban areas) interspersed with spontaneous development zones and large constructions or clusters built on blocks old land [6]. With a large area, narrow roads following the fishbone network structure, and a very high density of construction, spontaneous development zones act as "solid areas" in urban areas, which are nearly impossible for vehicles to travel through.

As a result, vehicles are often forced to use main roads, causing them to overload, causing congestion. Most of the large-scale constructions on old plots only contribute to increasing traffic pressure. Building multiple roads through spontaneous development zones is a basic solution to complete the Hanoi road network. However, due to the high cost of compensation, Hanoi is probably only able to clear the ground to open a number of main roads, spontaneous development zones will remain long-term. These areas will continue to hinder Hanoi's traffic - regardless of how the new urban area is built - if we don't know how to look it the other way. 


\section{Opportunities from the defects}

The nature of the development of spontaneous zones is to cling to the outer rim traffic, constantly encroaching in the open alleyways until they occupied all the vacant land. From outside to inside, the economic value of land plots decreases; the level of solidification of works also tends to decrease. For most spontaneous development plots, the core is the cheapest and easiest place to buy land to create a large plot of land [4]. The only thing that prevents these plots from being purchased and developed into apartments, or commercial centers, is that there is no convenient transportation.

If both creating convenient transportation and arranging more quality services, this core will become the ideal new residential areas because they are located between the new urban areas and the old center of Hanoi.

\section{Renovate the core of spontaneous development areas}

In a nutshell, the idea of improving the core of spontaneous development zones is as follows: main road;

Acquire, merge valuable land plots in the core to create a large plot of land with all alleys connecting to the

On the newly created large lot, construction of underground car parks, a system of quality walking spaces (indoors and outdoors) with quality, urban railway station, play and entertainment spaces, service works, high-rise apartment buildings (serving both the needs of resettlement on the spot);

Improve alleys to create quality walking spaces, connecting with other walking spaces; If possible, the urban railway station is located as close to the main road as possible to limit changes to urban railway lines, while still being well connected to the walk space system in the core;

In areas with very high construction density, especially the outer rim, the urban railway stations can be connected by monorail with small capacity going high and connected to the urban railway station.

Theoretically, this solution can significantly increase accessibility and core value. Due to the ability to gather large land funds at the core, it is possible to form a quality and safe walking space system for the area, which will not only be conveniently connected to the urban railway stations but also to the translation works $[5,6]$. Service and parking are further developed at the core. Doing it this way can not only create urban areas that really adapt to walking and public transport but can also help improve the quality of life, create more jobs, vitality, and attractiveness for the spontaneous development of urban areas. The core of spontaneous development zones is likely to become a chain of new centers, becoming a place to attract users from the old Hanoi center and from new urban areas, mainly through the walk and the urban railway system.

\section{CONCLUSION}

The idea of building metro networks and urban railways in big cities in Vietnam has been studied and put into planning nearly two decades ago. However, by 2016 in Hanoi, line 2A (Cat Linh - Ha Dong) and line 3 (Nhon - Hanoi Station) are under construction. It is expected that by the end of 2016, line $2 \mathrm{~A}$ will test drive the train to start serving passengers in mid-2017. Line 3 is delayed for the expected completion time from 2016 to 2018. In the city. In Ho Chi Minh City, only the elevated sections of Line 1 are under construction, while Line 2 has just started the construction of the package of "Building office buildings and ancillary works at Tham Luong Depot". Although enough capital has been allocated. The remaining lines are still in the project research phase, calling for investment capital, or deploying the preparation process.

The delay in the implementation of urban railway lines due to many reasons, such as inappropriate policy institutions to call for investment capital and project support, the clearance process is very slow, difficulties in the process of implementing the design - construction of the project, etc. In addition, due to the lack of a detailed underground space planning in other urban areas in our country, the control of the situation of occupying Using space in the ground is difficult.

Many measures to overcome difficulties have been implemented by the State, relevant ministries, branches, the People's Committee, and the railway management board of Hanoi and Ho Chi Minh City. Ho Chi Minh City implemented: Promoting more openly the process of calling for investment projects, adjusting the planning in accordance with the project reality, speeding up the process of handing over the project premises, strengthening, and improving capacity project implementation, mobilize, and appoint competent people to run the project, etc. Hopefully, these positive actions will help urban railway projects in Vietnam reach their destination quickly more, creating new landscapes for urban transport of Vietnam's two largest cities. 


\section{REFERENCE}

1. Government of the Socialist Republic of Vietnam. (2016). Decision 519/QD-TTg transport planning of Hanoi capital 2030-2050.

2. Government of the Socialist Republic of Vietnam. (1998). Decision 108/1998/QD-TTg approving the adjustment of the general planning of Hanoi Capital up to 2020.

3. Ky, P. V. (2009). Railway works. Hanoi: Transportation

4. "Nam Thang Long - Tran Hung Dao railway 11 years waiting for the approval of underground stations". Youth Online. September 24, 2019. Accessed September 27, 2019.

5. Ba Do. (2016). "The scene of the collapse of Nhon - Hanoi Railway Station crane". VnExpress Accessed October 8 , 2016.

6. Ky, P. V., Phong, L. H., Dat, T. Q., \& Chien, C. Q. (2015). Design of Urban Railway Station Works. Hanoi: Build. 